\title{
A Study on Heat Conductivity Behavior of Zirconia Filled Polyester Composites
}

\author{
Abhinav Mukherjee ${ }^{1}$, Anand Shukla ${ }^{2}$ \\ ${ }^{1,2}$ Vindhya Institute of Technology Jabalpur,
}

\begin{abstract}
A numerical simulation of the heat-transfer process within polyester matrix composite filled with micro-sized zirconia particles using finite element method is proposed in this thesis. Three-dimensional spheres-in-cube lattice array models are constructed to simulate the microstructure of composite materials with zirconia content ranging from about 1.41 to 11.31 vol\% and the effective thermal conductivities of the composites are estimated. A commercially available finite-element package ANSYS is used for this numerical analysis. The result shows that the effective thermal conductivity $\left(k_{\text {eff }}\right)$ increases with increase in the volume fraction of the zirconia in the polyester matrix. The simulated values are compared with calculated $\boldsymbol{k}_{\text {eff }}$ values obtained from other established correlations such as Rule-of-Mixture (ROM), Maxwell's model and Lewis Neilson model. Similar class of composite is fabricated for different filler loading and the conductivity values are measured experimentally as well for validating the developed numerical model. This study reveals that the incorporation of zirconia particles results in enhancement of thermal conductivity of polyester thereby increasing its heat transportation capability. This results that the new class of composite material can found its potential application in the microelectronics components.
\end{abstract}

Keywords: polyester matrix, zirconia, ANSYS, Polyester Composites.

\section{Introduction}

Composites are combinations of two materials in which one of the materials, called the reinforcing phase, is in the form of fiber sheets or particles and are embedded in the other material called the matrix phase. The primary functions of the matrix are to transfer stresses between the reinforcing fibers/particles and to protect them from mechanical and/or environmental damage whereas the presence of fibers/particles in a composite improves its mechanical properties such as strength, stiffness etc. A composite is therefore a synergistic combination of two or more microconstituents that differ in physical form and chemical composition and which are insoluble in each other. The objective is to take advantage of the superior properties of both materials without compromising on the weakness of either.

\section{Literature Review}

Hard particulate fillers consisting of ceramic or metal particles and fiber fillers made of glass are being used these days to dramatically improve the mechanical properties such as wear resistance, even up to three orders of magnitude [5]. Various kinds of polymers and polymer matrix composites reinforced with metal particles have a wide range of industrial applications such as heaters, electrodes [6], composites with thermal durability at high temperature [7] etc. These engineering composites are desired due to their low density, high corrosion resistance, ease of fabrication and low cost [8-10]. Similarly, ceramic filled polymer composites have been the subject of extensive research in last two decades. The inclusion of inorganic fillers into polymers for commercial applications is primarily aimed at the cost reduction and stiffness improvement [11,12]. Along with fiber-reinforced composites, the composites made with particulate fillers have been found to perform well in many real operational conditions. When silica particles are added into a polymer matrix to form a composite, they play an important role in improving electrical, mechanical and thermal properties of the composites $[13,14]$. Currently, particle size is being reduced rapidly and many studies have focused on how single-particle size affects mechanical properties [15-17]. The shape, size, volume fraction and specific surface area of such added particles have been found to affect mechanical properties of the composites greatly. In this regard, Yamamoto et al. [18] reported that the structure and shape of silica particle have significant effects on the mechanical properties such as fatigue resistance, tensile and fracture properties. Nakamura et al. [19-21] discussed the effects of size and shape of silica particle on the strength and fracture toughness based on particle-matrix adhesion and also found an increase of the flexural and tensile strength as specific surface area of particles increased.

\section{Material Considered}

\subsection{Matrix Material (Polyester)}

Unsaturated isophthalic polyester supplied by Reliance India Ltd. is taken as the matrix materials in the present investigation. Unsaturated isophthalic polyester resinPolyester is a category of polymer which contains the ester functional group in their main chain. The term unsaturated polyester resin is generally referred to the unsaturated (means containing chemical double bonds) resins formed by the reaction of dibasic organic acids and polyhydric alcohols. Polyester resin is also known as a thermosetting plastic, which implies the plastic sets at high temperatures

\subsection{Filler Material (Zirconium dioxide)}

Zirconium dioxide $\left(\mathrm{ZrO}_{2}\right)$, sometimes known as zirconia (not to be confused with zircon), is a white crystalline oxide of zirconium.

\section{Volume 4 Issue 12, December 2015}




\section{International Journal of Science and Research (IJSR) \\ ISSN (Online): 2319-7064}

Index Copernicus Value (2013): 6.14 $\mid$ Impact Factor (2014): 5.611

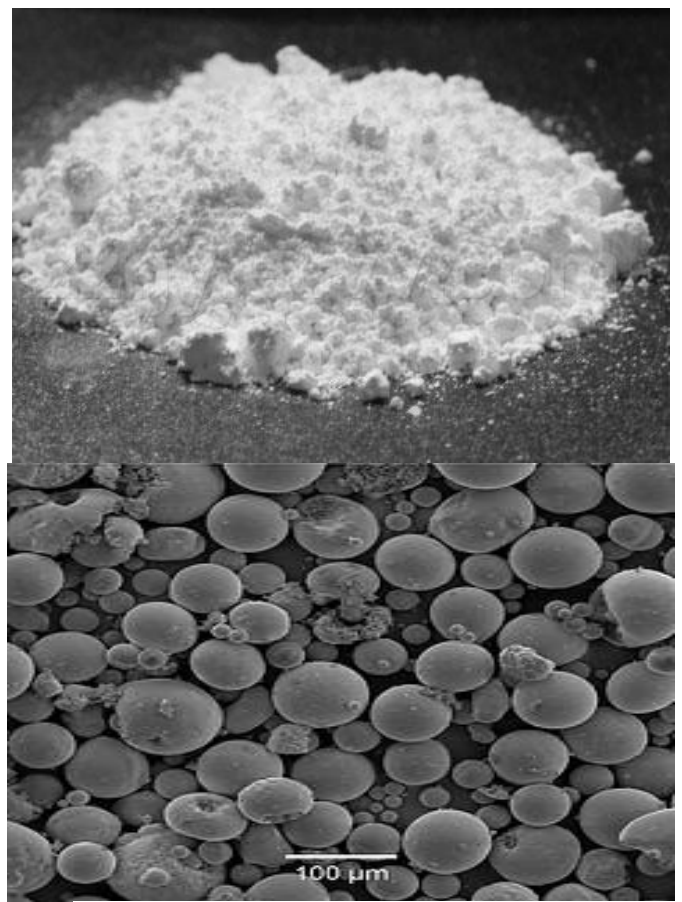

Figure 1: Zirconium dioxide powder and its microstructure

Its most naturally occurring form, with a monoclinic crystalline structure, is the mineral baddeleyite. A dopant stabilized cubic structured zirconia, cubic zirconia, is synthesized in various colours for use as a gemstone and a diamond simulant. Zirconia is chemically unreactive. Zirconium dioxide is one of the most studied ceramic materials. $\mathrm{ZrO}_{2}$ adopts a monoclinic crystalstructure at room-temperature and transitions to tetragonal and cubic at higher temperatures.

\subsection{Composite Fabrication}

Composite samples of various compositions are prepared by hand lay-up technique. Hand lay-up technique is the oldest and simplest technique for composite fabrication. The polyester-zirconia composites are prepared in the following steps (i) uncured polyester and its corresponding hardener is mixed in a ratio of 10:1 by weight as per recommendation. (ii) Micro-sized zirconia particles are mixed with the polyester in different proportions. (iii) The uniformly mixed dough (polyester filled with zirconia) is then slowly decanted into the glass molds so as to get disc type specimens (diameter $50 \mathrm{~mm}$ and thickness $3 \mathrm{~mm}$ ) coated beforehand with wax and a uniform thin film of silicone-releasing agent. (iv) The castings are then left at room temperature for about 24 hours and then the glass molds are broken and the samples are released.
Table 1: Polyester composites filled with micro-sized zirconia powder

\begin{tabular}{|c|c|}
\hline S. No. & Composition \\
\hline 1 & Neat polyester \\
\hline 2 & Polyester $+1.41 \mathrm{vol} \% \mathrm{ZrO}_{2}$ \\
\hline 3 & Polyester $+3.35 \mathrm{vol} \% \mathrm{ZrO}_{2}$ \\
\hline 4 & Polyester $+5.236 \mathrm{vol} \% \mathrm{ZrO}_{2}$ \\
\hline 5 & Polyester $+7.85 \mathrm{vol} \% \mathrm{ZrO}_{2}$ \\
\hline 6 & Polyester $+9.42 \mathrm{vol} \% \mathrm{ZrO}_{2}$ \\
\hline 7 & Polyester $+11.31 \mathrm{vol} \% \mathrm{ZrO}_{2}$ \\
\hline
\end{tabular}

\section{Numerical Analysis}

In the numerical analysis of the heat conduction problem, the temperatures at the nodes along the surfaces $\mathrm{ABCD}$ is prescribed as $\mathrm{T}_{1}\left(=100^{\circ} \mathrm{C}\right)$ and the convective heat transfer coefficient is assumed to be $2.5 \mathrm{~W} / \mathrm{m}^{2}-\mathrm{K}$ at ambient temperature of $27^{\circ} \mathrm{C}$. The heat flow direction and the boundary conditions are shown in Fig. 2.

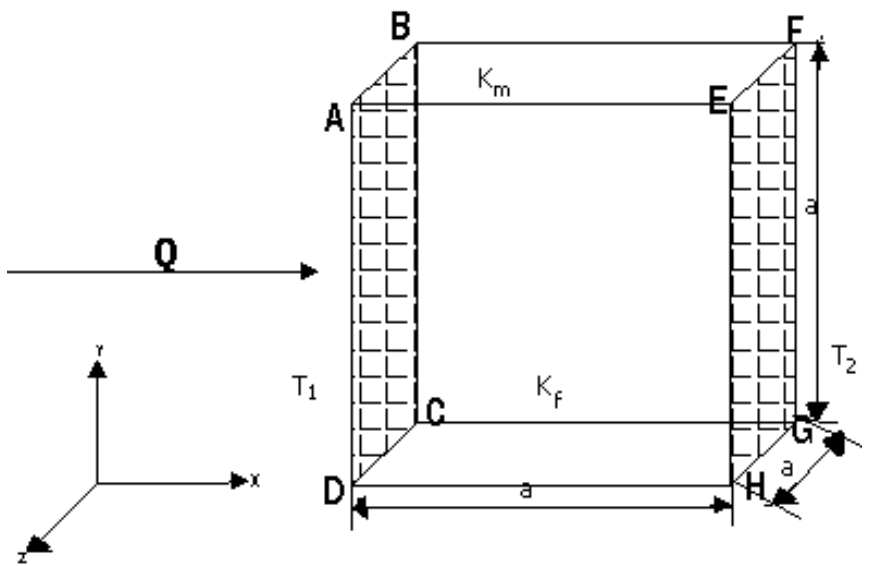

Figure 2: Boundary conditions

Thermal conductivities of polyester composites filled with micro size zirconia particles up to $11.3 \%$ by volume are numerically estimated by using the spheres-in-cube model. A typical 3-D model showing arrangement of spherical fillers with a particle concentration of $3.35 \mathrm{vol} \%$ within the cube shaped matrix body is illustrated in Fig.3. The temperature profiles obtained from FEM analysis for the composites (spheres-in-cube arrangement) with particulate concentrations of $1.4,3.35$, vol. \% are presented in Figs. $4-5$ respectively.

Table 2: Equivalent thermal conductivities obtained from different methods

\begin{tabular}{|c|c|c|c|c|c|c|}
\hline \multirow{2}{*}{$\begin{array}{c}\text { Sr. } \\
\text { No }\end{array}$} & \multirow{2}{*}{$\begin{array}{l}\text { Zirconia } \\
\text { particles } \\
\text { (vol. \%) }\end{array}$} & $\begin{array}{c}\text { Rule of } \\
\text { mixture model }\end{array}$ & Maxwell's model & $\begin{array}{c}\text { Lewis and } \\
\text { Neilson model }\end{array}$ & FEM Simulation & Experimental Result \\
\hline 2 & 1.41 & 0.215 & 0.221 & 0.219 & 0.234 & 0.231 \\
\hline 3 & 3.35 & 0.219 & 0.234 & 0.231 & 0.249 & 0.245 \\
\hline 4 & 5.236 & 0.224 & 0.247 & 0.242 & 0.268 & 0.261 \\
\hline 5 & 7.85 & 0.23 & 0.265 & 0.26 & 0.291 & 0.284 \\
\hline 6 & 9.42 & 0.234 & 0.277 & 0.271 & 0.332 & 0.321 \\
\hline 7 & 11.31 & 0.239 & 0.292 & 0.286 & 0.388 & 0.375 \\
\hline
\end{tabular}




\section{International Journal of Science and Research (IJSR) \\ ISSN (Online): 2319-7064}

Index Copernicus Value (2013): 6.14 $\mid$ Impact Factor (2014): 5.611

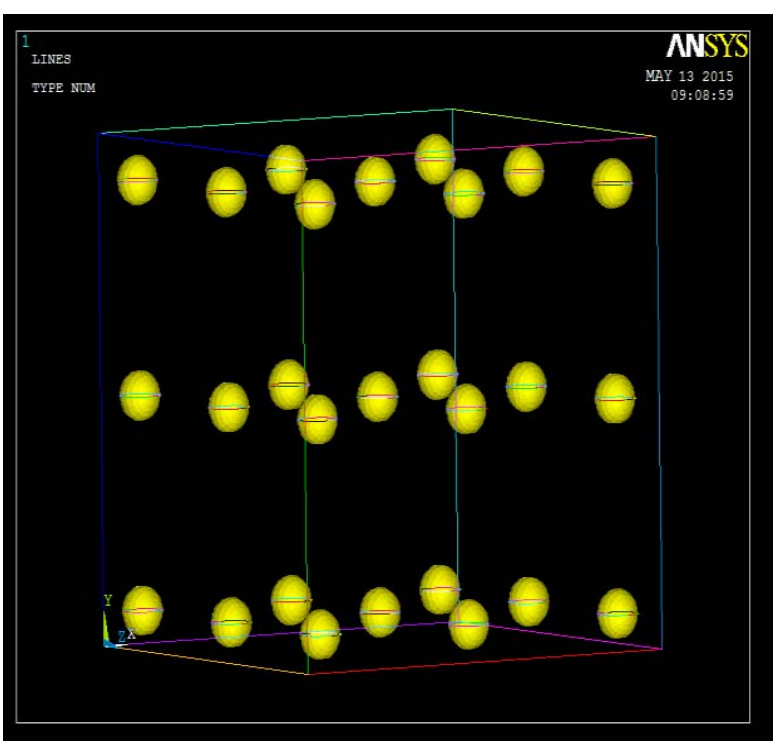

Figure 3: A typical 3-D spheres-in-cube model

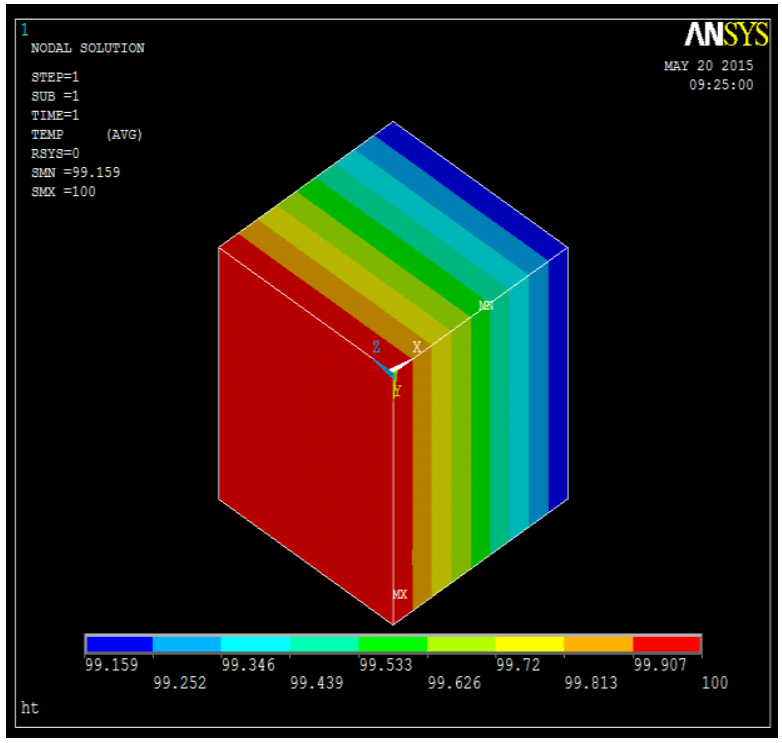

Figure 4: Temperature profile for composite with particle concentration of $1.4 \mathrm{vol} \%$

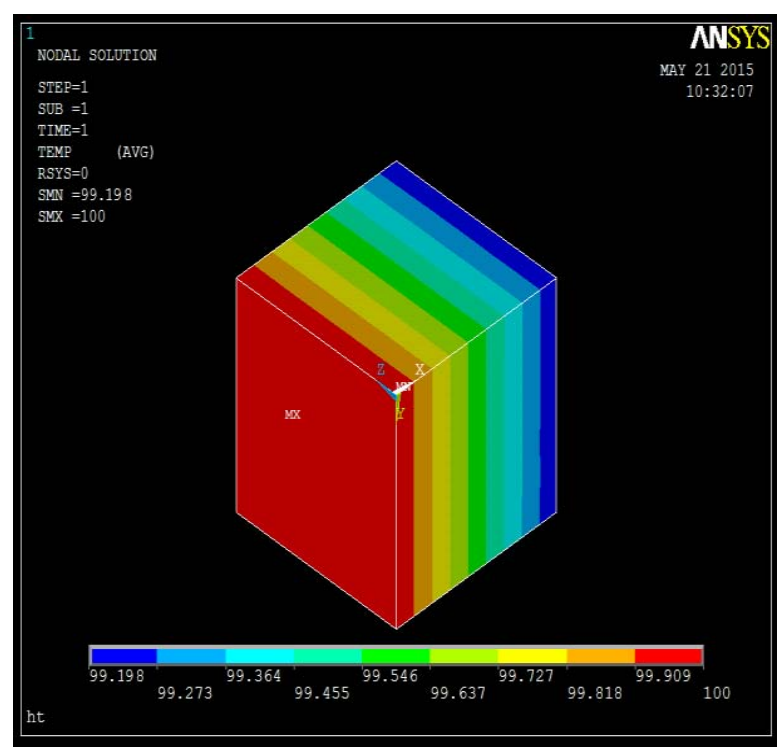

Figure 5: Temperature profile for composite with particle concentration of $3.35 \mathrm{vol} \%$

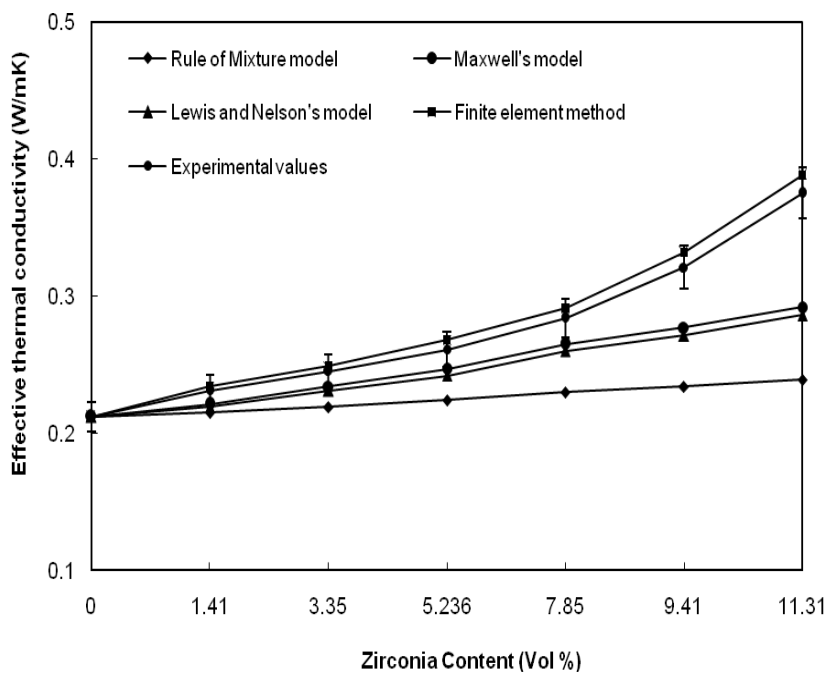

Figure 6: Equivalent Thermal conductivity of $\mathrm{ZrO}_{2}$ /Polyester: FEM results, Rule of mixture, Maxwell's Model, Lewis and Neilson model and Experimental values

It can be seen from the graph that for less filler concentration, the slope of the curve is less and as the filler volume fraction increases, the curves representing FEM and experimental values become steeper. It might be due to the fact that with increase in filler concentration, the inter-particle distance reduces and the conductive chains begin to form which increase the thermal conductivity quite reasonably.

Table 3: Percentage errors with respect to the experimental values

\begin{tabular}{|c|c|c|c|c|}
\hline \multirow[b]{2}{*}{ Sr. No. } & \multicolumn{4}{|c|}{ Equivalent thermal conductivity associated error (\%) } \\
\hline & $\begin{array}{c}\text { Rule of } \\
\text { mixture } \\
\text { model }\end{array}$ & $\begin{array}{l}\text { Maxwell's } \\
\text { model }\end{array}$ & $\begin{array}{c}\text { Lewis and } \\
\text { Neilson } \\
\text { model }\end{array}$ & $\begin{array}{c}\text { FEM } \\
\text { Simulation }\end{array}$ \\
\hline 1 & 6.9 & 4.32 & 5.19 & 1.29 \\
\hline 2 & 10.6 & 4.48 & 5.71 & 1.63 \\
\hline 3 & 14.17 & 5.36 & 7.28 & 2.68 \\
\hline 4 & 19.01 & 6.69 & 8.45 & 2.46 \\
\hline 5 & 27.10 & 13.71 & 15.57 & 3.42 \\
\hline 6 & 36.26 & 22.13 & 23.73 & 3.46 \\
\hline
\end{tabular}

\section{Conclusions}

This numerical investigation has led to the following specific conclusions:

Finite element method can be gainfully employed to determine equivalent thermal conductivity of these composite with different amount of filler content. A good agreement of FEM results with those obtained from experimental efforts validates the usefulness of this numerical method.

Incorporation of zirconia particles results in increase of thermal conductivity of polyester and thereby improves its conduction capability. With addition of $1.41 \mathrm{vol} \%$ of $\mathrm{ZrO}_{2}$ particle (100 micron size), the thermal conductivity increases by about $9 \%$ as compared to neat polyester and it increases by as high as $77 \%$ by adding $11.31 \%$ of same particle. 


\section{International Journal of Science and Research (IJSR) \\ ISSN (Online): 2319-7064 \\ Index Copernicus Value (2013): 6.14 | Impact Factor (2014): 5.611}

This new class of zirconia particle filled polyester composites can be used for applications such as thermal fuses, electronic packaging etc.

\section{Scope for Future Work}

This work leaves a wide scope for future investigators to explore many other aspects of thermal behavior of particulate filled composites. Some recommendations for future research include:

Effect of filler shape on thermal conductivity of the composites. Exploration of new fillers and polymers for development of materials having high thermal conductivity.

\section{References}

[1] Nakamura Y, Yamaguchi M, Okubo M and Matsumoto $\mathrm{T}(1991)$. Effect of particle size on impact properties of epoxy resin filled with angular shaped silica particles. Polymer, 32: 2976-2979.

[2] Nakamura Y, Yamaguchi M, Okubo M Tummala RR and Rymaszewski EJ (1989). Microelectronic packaging handbook. New York, Van Nostrand Reinhold, 523658.

[3] Kim W, Bae JW, Choi ID, and Kim YS (1999). Thermally conductive EMC for microelectronic encapsulation. Polymer Engineering Science, 39: 756766.

[4] Lee ES, Lee SM, Shanefield DJ and Cannon WR (2008). Enhanced thermal conductivity of polymer matrix composite via high solids loading of aluminium nitride in epoxy resin. Journal of American Ceramic Society, 91: 1169-1174.

[5] Xu Y, Chung DDL and Mroz C (2001). Thermally conductive aluminium nitride polymer matrix composites. Composites: Part A, 32: 1749-57.

[6] Gregory SW, Freudenberg KD, Bhimaraj P and Schadler LS (2003). A study on the friction and wear behavior of PTFE filled with alumina nanoparticles. Wear, 254: 573-580.

[7] Jung-il K, Kang PH and Nho YC (2004). Positive temperature coefficient behavior of polymer composites having a high melting temperature. Journal of Applied Polymer Science, 92: 394-401.

[8] Nikkeshi S, Kudo M and Masuko T (1998). Dynamic viscoelastic properties and thermal properties of powderepoxy resin composites. Journal of Applied Polymer Science, 69: 2593-2598.

[9] Zhu K and Schmauder S (2003). Prediction of the failure properties of short fiber reinforced composites with metal and polymer matrix, Computational Material Science, 28: 743-748.

[10]Rusu M, Sofian N and Rusu D (2001). Mechanical and thermal properties of zinc powder filled high density polyethylene composites, Polymer Testing, 20: 409-417.

[11] Tavman IH (1997). Thermal and mechanical properties of copper powder filled poly (ethylene) composites. Powder Technology, 91: 63-67.
[12]Rothon RN (1997). Mineral fillers in thermoplastics: filler manufacture. Journal of Adhesive Material, 64: 87-109.

[13] Rothon RN (1999). Mineral fillers in thermoplastics: filler manufacture and characterization. Advancement in Polymer Science, 139: 67-107. 